\title{
ACERVOS ACADÊMICOS DE PESQUISA: POSSIBILIDADES E DESAFIOS
}

\section{ACADEMIC RESEARCH COLLECTIONS: POSSIBILITIES AND CHALLENGES}

\begin{abstract}
Ana Maria Veiga*
Resumo: Este artigo explora as possibilidades e desafios para os acervos acadêmicos de pesquisa - conjuntos de documentos acumulados e produzidos por grupos e núcleos de pesquisa dentro das universidades ao longo do desenvolvimento de suas próprias investigações -, tratando dos aspectos de sua constituição, seus problemas técnicos, e também das possibilidades inerentes de preservação e divulgação do material coletado e produzido dentro desses núcleos, em contexto universitário, privilegiando aqui o campo da História. Partindo das questões sobre o armazenamento físico desse material, passando por sua digitalização e chegando aos desafios atuais da disponibilização virtual, buscaremos refletir sobre a função social de tais acervos, dentro e fora da academia, tendo como meta a preocupação de, com eles, abrir um caminho de acesso entre os núcleos de pesquisa, a produção que deles deriva e a sociedade - representada pelas pessoas que possam se interessar por uma vasta gama de informações, que promove pesquisas e torna viável o ensino e a escrita da História.
\end{abstract}

Palavras-chave: Acervos acadêmicos. Pesquisa. Digitalização. Publicação. História.

\footnotetext{
* Professora substituta no Departamento de História da Universidade Federal de Santa Catarina (UFSC).E-mail: amveiga@yahoo.com.br
} 


\begin{abstract}
This article explores the possibilities and challenges for academic research collections - a set of documents accumulated and produced by researching centers and groups inside universities over the development of their own investigations -, dealing with some aspects of its constitution, its technical problems, and also the inherent possibilities of preservation and disclosure of collected and produced materials inside researching centers at the university, privileging here History field. Starting from some questions on the physical storage of materials, passing by its digitalization and getting to the current challenges of making them available, we will try to construct a reflection on these scholar research collections social function, in and outside academy, aiming the preoccupation of, through them, open an access path among researching centers, the material they produce and society - represented by people which may be interested in a wild range of information, that can promote researches and become viable History teaching and writing.
\end{abstract}

Keywords: Academic collections. Research. Digitalization. Publication. History.

\title{
I. POSSIBILIDADES
}

Pensar os laços entre acervos e investigação histórica é refletir sobre o próprio métier dos historiadores. Desde que a perspectiva da variedade de fontes para a pesquisa histórica foi ampliada, ainda na primeira metade do século XX, com as propostas da primeira geração da Escola dos Annales, nos encontramos diante de um leque de possibilidades, que nos permite transitar por vias de escolhas múltiplas, a serem atravessadas por nossa subjetividade e nosso posicionamento político.

O conceito 'acervo de pesquisa' sofreu modificações importantes neste último século, rompendo os limites dos pensamentos comtiano e cientificista e seus métodos, cuja influência acabava por cercear a atuação dos historiadores, restritos então à busca e à análise de documentos oficiais cunhados dentro das esferas hegemônicas de poder. Não queremos sugerir que esse tipo de documentação tenha sido banido do campo da pesquisa histórica, mas os desafios lançados no decorrer desse período trouxeram em seu bojo a necessidade de reelaboração daquilo que pode ser considerado hoje um acervo de pesquisa. O que antes se restringia a práticas individuais, a anotações e acervos próprios, de pequeno porte, alcançou a proporção de conjuntos maiores, que se tornaram viáveis devido às possibilidades e incentivos para a pesquisa, desenvolvida em torno de projetos que mobilizam núcleos de estudos situados no interior das universidades. O material de investigação privado, dos professores e professoras, passaram a ser disponibilizados para 
os participantes de seus núcleos de pesquisa, entre eles estudantes e outros professores agregados.

Reunir, organizar e arquivar documentos, materiais avulsos ou encontrados em séries e coleções, por vezes produzidos para pesquisas determinadas - como o exemplo das entrevistas de história oral -, é uma prática bastante difundida no tempo presente. Esses 'garimpos' da história vão se constituindo em acervos que, com maior ou menor dimensão, passam a fazer parte das opções de investigação e da produção de conhecimento.

Ao lado de arquivos de porte maior, constituídos ao longo do tempo, como os casos do Centro de Pesquisa e Documentação da Fundação Getúlio Vargas (CPDOC) e da Cinemateca Brasileira, para citar alguns conhecidos, podemos situar aqueles que tiveram um processo mais recente de consolidação, dentro e fora do país, como o Centro de Documentación e Investigación de la Cultura de Izquierdas - CeDInCI - constituído em Buenos Aires depois da última ditadura militar na Argentina. $\mathrm{O}$ caso desse centro é relevante, pois ele reúne hoje uma hemeroteca, uma biblioteca e um arquivo de documentos relacionados aos movimentos de esquerda em seu país, sendo, ao mesmo tempo, amplo e temático.

Tais centros de documentação oferecem, de maneira organizada, matéria prima para a pesquisa histórica. No entanto, Cláudia Heynemann alerta: "somos conduzidos a pensar a relação com a memória como catalizadora para as análises de nossos campos de conhecimento, suas intertextualidades e as perspectivas que a escrita da história hoje encontra nos arquivos". ${ }^{1}$ Para Krzysztof Pomian, "[...] a oposição entre a memória e a história permeia o próprio processo de gestão de documentos até a liberação dos documentos à consulta”. A partir daí, "o passado se torna propriedade de todos e objeto da história." Os arquivos seriam, antes de tudo, objetos da história, não da memória. Seu uso intelectual aponta ainda para a "íntima relação entre os historiadores e os arquivos". 2 Heynemann propõe que se interrogue a historiografia em sua leitura dos documentos, obrigando-a a

[...] reconhecer as relações, o diálogo, a forma e o estilo, a autonomia de imagens e as imagens dentro do texto, escapando de uma linearidade, da organização sucessiva, de um tempo vazio preexistente. Podemos assim retomar a própria lógica da leitura, desdobrando o sentido inicialmente estabelecido. ${ }^{3}$

Mas, e quando a leitura se dá sobre elementos autorreferentes? Já retornaremos a esta questão.

A relação dos arquivos com a pesquisa histórica também é discutida por Carlos Bacelar, que entende que muitas vezes os acervos não estão preparados 
para o trabalho de consulta acadêmica. Para além da documentação localizada nos arquivos públicos, o autor argumenta que

[...] outros conjuntos documentais de grande importância podem ser encontrados ainda nas instituições produtoras e acumuladoras originais, como Ministérios, Secretarias de Estado e Municipais, Assembleias Legislativas, Prefeituras, Câmaras Municipais, Tribunais de Justiça, fóruns, cartórios, cúrias, além de indústrias, empresas e pessoas físicas. ${ }^{4}$

Observamos em seu texto a ausência das universidades entre as instituições "produtoras e acumuladoras" de acervos documentais. Para Bacellar, "documentos do passado não foram elaborados para o historiador, mas sim para atender a necessidades específicas do momento". ${ }^{5}$

Propomos uma reelaboração desse argumento, pensando em documentos forjados pelos/para os historiadores nas últimas décadas, a partir dos quais eles passaram a trabalhar. Esta é a principal reflexão proposta neste artigo, que se torna pertinente diante das práticas atuais de núcleos acadêmicos de pesquisa, especialmente na área da História e das demais Ciências Humanas, que acumulam e por vezes produzem (para si) seu próprio material de trabalho. Além de suprir as necessidades de seus membros (em sucessivas gerações dentro do ciclo acadêmico), a documentação produzida também pode ser disponibilizada para a comunidade universitária, assim como para outros interessados nas temáticas abordadas.

Ocorre aqui uma possível transgressão no reconhecimento da utilidade dos arquivos. De locais legitimadores e pontos de partida para o fazer historiográfico, tornam-se espaços a serem também ocupados por acervos resultantes desse tipo de trabalho. Sua relação intrínseca com o poder - quem escolhe aquilo que deve ser guardado e preservado, para então ser rememorado? - é de certo modo invertida e investida de outra qualidade de reivindicação.

É o material forjado no esforço de um saber produzido ${ }^{6}$, vinculado às universidades, que se autovalora e se busca constituir como acervo. Isso sinaliza a construção de uma relevância para determinado campo de pesquisa e uma autoridade legitimadora para seu núcleo produtor, considerando o que Michel Foucault argumenta sobre as relações entre 'saber' e 'poder'7, ambos instituídos socialmente e trabalhando no sentido de se constituir esferas de poder ou "regimes de verdade". ${ }^{8}$ Portanto, acervos acadêmicos de pesquisa podem ser tomados como arquivos de materiais justificadores da constituição de um 'saber' em nível universitário, que reivindica para si um lugar na esfera de 'poder' intelectual, transcendendo, ou não, os limites da academia.

Esses acervos privilegiam objetos encontrados, selecionados, registrados e catalogados como parte de um conjunto, por vezes uma série documental. 
Podem ser eles peças utilitárias, fotografias, testemunhos gravados, entre outros tipos de materiais.

Para Anthony Seeger, o trabalho de formação de um acervo requer a combinação de conhecimentos, como o de biblioteconomia (para a dimensão da organização), habilidades técnicas (para a preservação), domínio de leis (para as questões de propriedade intelectual) e a capacidade de promoção, para que ocorra o acesso em escala maior. ${ }^{9}$

Após esta breve visão do trabalho necessário à realização do nosso presente objeto de estudo, passamos a tratar deles, os acervos que podem ser encontrados no interior das universidades - aqui denominados 'acervos acadêmicos' -, organizados dentro de núcleos de pesquisa, como já foi mencionado.

Para Seeger, "tanto arquivos há muito estabelecidos como os que estão em fase de planejamento e desenvolvimento enfrentam problemas similares no que se refere a aquisição, catalogação, manutenção e migração de formatos, bem como a restrições relativas à propriedade intelectual'". ${ }^{10}$ Estas questões são centrais para os tipos de acervos com os quais lidamos neste artigo.

Arlette Farge, por sua vez, busca digerir as mudanças impostas pela 'modernidade' ao trabalho dos pesquisadores nos arquivos.

Examinar o arquivo, folheá-lo, ir de trás para frente torna-se impossível agora com essa técnica impiedosa que modifica sensivelmente sua leitura, e portanto sua interpretação. Úteis para a conservação, esses sistemas de reprodução do arquivo permitem evidentemente outras maneiras fecundas de colocar questões aos textos, mas farão com que alguns esqueçam a abordagem tátil e imediata do material, essa sensação preensível de vestígios do passado. O arquivo manuscrito é um material vivo, enquanto sua reprodução microfilmada é um pouco letra morta, ainda que se revele necessária. Ler o arquivo é uma coisa, encontrar o meio de retê-lo é outra. ${ }^{11}$

Com ela, somos remetidos a reflexões sobre o nosso próprio meio e 'ofício', como lidar com a apresentação e o suporte - em constante transformação - do material a ser consultado. Tais questionamentos nos levam a recapitular os passos necessários à formulação de uma pesquisa histórica. E voltamos à crítica das fontes, aos trabalhos da memória, às reflexões sobre cultura e sociedade, à flexibilidade diante de desafios e inovações, buscando não permitir que a lei da gravidade dos resquícios de um pensamento ligado estritamente às diretrizes do cientificismo, da linearidade e da razão - e do qual ainda tentamos nos livrar -, nos atinja.

Ao seguirmos adiante, dentro da especificidade do tema proposto neste artigo, outro questionamento se faz necessário à aproximação com o objeto. 


\section{COMO SE CONSTITUEM ACERVOS EM ÂMBITO ACADÊMICO?}

Este trabalho orbita em torno do estudo do processo de constituição, organização e uso de acervos de pesquisa no âmbito universitário, como prática científica, entendendo esses acervos enquanto resultados de esforços coletivos que envolvem professores e estudantes como investigadores, 'produtores' de fontes e propagadores de conhecimento a ser apropriado e divulgado através de pesquisas e publicações, dentro e fora da universidade.

Para serem eficientes, os arquivos necessitam melhorar sua acessibilidade e tomar providências para preservar com máximo cuidado as coleções, de tal modo que elas estejam disponíveis quando alguém requisitar sua utilização como alerta Seeger. ${ }^{12}$

Como sinalizamos anteriormente, montar um acervo acadêmico envolve bem mais do que apenas coletar material que proporcione a produção científica. A divulgação do conhecimento passou ao primeiro plano dos interesses de muitos núcleos, principalmente com o domínio de ferramentas digitais. Mas, para se chegar a esse nível, foi necessário percorrer um longo caminho, desde os métodos tradicionais (como fichas, anotações, fotocópias de documentos, gravação em fita cassete $\left.{ }^{13}\right)$ até o uso de outras tecnologias, como câmeras e gravadores digitais, computadores e, mais recentemente, o armazenamento do acervo nas chamadas 'nuvens' virtuais - mais seguras e econômicas em termos de gastos e de espaço físico. Os portais e repositórios virtuais vão tomando o espaço (ou reduzindo a materialidade) dos grandes arquivos, que antes necessitavam de lugar amplo para armazenamento e consulta do material. Isto faz parte de um dos processos aos poucos desvendados por alguns artigos deste dossiê, que buscam questionar, confrontar e analisar algumas etapas da constituição de acervos e seu uso, agregando conhecimento por meio da interdisciplinaridade nele proposta.

Um acervo acadêmico é composto de materiais diversos, que podem ser transferidos/importados de outros arquivos (por meio de fotografias digitais de documentos, que aos poucos substituem as ainda existentes fotocópias, etc.); adquiridos (por meio de compra ou doação); ou produzidos (como no caso de entrevistas orais voltadas para pesquisas específicas dos grupos envolvidos em sua produção).

No caso da documentação transferida/importada para o acervo acadêmico, o contato com funcionários dos arquivos de origem e sua colaboração tornam-se fundamentais, bem como a consulta a catálogos disponíveis sobre os temas recortados. Já quando lidamos com material produzido pelos núcleos de pesquisa, são os entrevistados e os intermediários desses contatos que tomam lugar central.

A produção de seu próprio material é o que gera especificidade desse tipo de acervo na comparação com outros tipos disponíveis para a pesquisa 
histórica. Como se estabelecem as possíveis especificidades dos arquivos acadêmicos é a pergunta à qual buscaremos responder a seguir, especificando alguns elementos que aparecem com frequência na documentação que circula dentro e através dos núcleos de pesquisa.

\section{O TRABALHO COM ENTREVISTAS ORAIS}

Em diversos acervos acadêmicos, ao lado de outros tipos de documentação, encontramos uma das ferramentas de trabalho incontornáveis para a história do tempo presente, que aos poucos se consolida em torno da matéria viva da história, no sentido literal do termo contemporaneidade. Estamos falando de testemunhos orais, tratados pelos métodos da história oral, que acabam sendo cada vez mais utilizados no trabalho com memórias, individuais e coletivas, registradas, guardadas e transcritas para virarem matéria prima da historiografia e, por que não, do ensino de história.

Ao lado desse material, fotografias, panfletos, jornais, revistas, por vezes filmes ou vídeos fornecem elementos para um diálogo frutífero com as fontes orais, enriquecendo a pesquisa histórica sobre os mais variados temas, pessoas, grupos e lugares. Recortes sociais são realizados e servem como ponto de partida para se compreender práticas, relações, conflitos e experiências. Nesses cruzamentos, estudantes e profissionais da história se deparam com problemas e obstáculos que devem ser considerados quando se pensa em histórias perpassadas por lembranças, esquecimentos, desvios ou mesmo espaços vazios.

Antes de mais nada, testemunhos orais são fontes produzidas pelos próprios historiadores, ou com as quais eles se deparam em sua trajetória de pesquisa. No caso da investigação acadêmica, elas marcam a especificidade na constituição de acervos temáticos. Memórias são evocadas conforme circunstâncias, adquirindo posicionamentos a partir de seus registros. Michael Pollak menciona o "trabalho de enquadramento da memória". Para este autor, "manter a coesão interna e defender as fronteiras daquilo que um grupo tem em comum, em que se inclui o território, eis as duas funções essenciais da memória comum". ${ }^{14}$

Entendemos como 'comum' o compartilhamento de um contexto, com traços gerais que podem ser relacionados, mas que é, ao mesmo tempo, permeado por singularidades encontradas em cada lugar e em cada experiência individual.

Já para Alessandro Portelli, “a história oral e as memórias não nos oferecem um esquema de experiências comuns, mas sim um campo de possibilidades compartilhadas, reais ou imaginárias". ${ }^{15}$ Portanto, não há uma só e acertada visão dos fatos, pois um evento gera múltiplas visões, relatos e interpretações. 
O narrar-se também deve ser colocado em questão, como faz Margareth Rago no livro A aventura de contar-se: feminismos, escrita de si e invenções da subjetividade. Nele, a autora propõe "problematizar as narrativas vivenciais constitutivas da própria subjetividade e explorar a dimensão narrativa da construção do eu na objetivação da experiência”, ou seja, como suas entrevistadas se constituem como sujeitos, como recortam o passado, quais experiências querem valorizar ou silenciar. ${ }^{16}$ Philippe Lejeune ${ }^{17}$, citado também por Rago, entende que os relatos de vida gravados e publicados ajudam a transpor os limites das narrativas dominantes.

Relatos autobiográficos reelaboram o passado para dar sentido ao presente. Para Pierre Bourdieu, a vida não pode ser organizada como história, no sentido de 'verdade' ou de uma sequência linear de acontecimentos. A vida como história é uma ilusão retórica, adotada com frequência no 'falar de si', na 'produção de si'. ${ }^{18}$

Portanto, a 'fabricação' desse tipo de material de pesquisa com base em testemunhos é acompanhada, em seu processo interno, por uma metodologia ${ }^{19}$, traçada desde a elaboração de um questionário que atenda às demandas da investigação, atravessada por questionamentos, como os colocados acima, e finalizada por uma transcrição (etapa não obrigatória) e pela autorização de publicação da entrevista.

A abordagem e a apresentação às pessoas que serão entrevistadas constituem momentos decisivos para os rumos da pesquisa. Uma vez cumprida essa etapa, as entrevistas, tecnicamente falando, podem ser gravadas em áudio, agregado ou não ao recurso visual. Numa fase posterior, os esforços giram em torno da organização, da transcrição, do armazenamento e das estratégias de disponibilização do material. Sem dúvida, a centralidade da cultura visual ${ }^{20}$ na contemporaneidade aponta para novos caminhos quando a meta é a divulgação de resultados do trabalho. Neste caso, o material pode também ser editado e disponibilizado em vídeo.

Seeger, pautado em sua experiência com material sonoro, esclarece alguns passos: à pessoa entrevistada deve ser solicitada a assinatura de uma "autorização transferindo os direitos sobre as gravações para o arquivo e indicando o grau de acessibilidade permitido a cada material." $\mathrm{O}$ autor considera diferentes níveis de restrição, indo do acesso aberto, ao uso não-comercial, até a proibição absoluta de acesso. ${ }^{21}$

Autorizações e suas preciosas assinaturas também se tornam material a ser arquivado pela burocracia própria que rege o funcionamento dos acervos de pesquisa. Paralelamente ao trabalho de captação e organização dos testemunhos orais, desenvolve-se o procedimento crítico e analítico de tais fontes produzidas e o estudo do melhor meio de disponibilizá-las para novas pesquisas e também para a consulta externa, quando assim permitido.

As fontes orais são documentos indispensáveis para pesquisadores que se interessam por indivíduos ou grupos que não tiveram lugar na historiografia 
tradicional. Por este motivo, aparecem atualmente com frequência nos acervos acadêmicos de pesquisa.

Como complemento a esse tipo de fonte, vamos agora pensar em termos de imagens na constituição desses acervos.

\section{O TRABALHO COM IMAGENS E MATERIAL AUDIOVISUAL}

O uso de imagens e de material audiovisual como documentos para a história aparece em boa parte das pesquisas na atualidade. Nos acervos que se constituem em âmbito acadêmico podemos encontrar imagens produzidas nas mais diversas situações; são elas fotografias, charges ou reproduções que estampam periódicos ou folhetos, mas também podemos neles localizar imagens produzidas e utilizadas como ferramentas de pesquisa adotadas nas últimas décadas - são as fotos digitais, que reproduzem documentos, substituindo fichas e fotocópias (xerox), e que constituem acervos. A câmera fotográfica digital tornou-se equipamento indispensável aos pesquisadores, reduzindo a horas os dias passados dentro dos arquivos, onde as fontes antes eram pacientemente fichadas.

O que se ampliou, por outro lado, foi o tempo dedicado à análise dessas fotografias - representações e registros dos documentos originais -, agora realizada em casa ou no interior de um núcleo de estudos. O que era visto apenas pelo pesquisador passa a ser democratizado dentro de seu grupo, circula nos computadores, nos repositórios virtuais, é amplamente discutido, até virar dados traduzidos, analisados e interpretados na produção escrita. A possibilidade ilimitada de se voltar à fonte, sua 'nova' acessibilidade, transforma a metodologia e a prática empírica da pesquisa.

Peter Burke questiona: "Em que medida e de que formas as imagens oferecem evidência confiável do passado?" O autor argumenta que nós ignoramos a variedade de imagens, seus produtores, usos e as atitudes para com elas em diferentes períodos da história ${ }^{22}$, portanto cabe-nos, como historiadores, cercarmos suas possibilidades, buscando aproximá-las de outros elementos disponíveis à investigação.

Discordamos de Burke quando ele sugere que o cruzamento com outros documentos é 'necessário' para legitimar o uso de imagens nas análises históricas. Acreditamos que uma única imagem pode gerar importantes reflexões por meio de sua análise, sempre ligada à inserção contextualizada desse tipo de objeto no meio onde foi produzido.

A produção audiovisual muitas vezes faz parte também do material encontrado em acervos acadêmicos, seja como registro de entrevistas ou mesmo de atividades promovidas pelo grupo de pesquisa - como palestras e encontros - em âmbito universitário ou gravados durante o trabalho de campo. 
As possibilidades são variadas e incrementadas pela tecnologia móvel dos aparelhos celulares, câmeras fotográficas, notebooks e tablets, que contêm câmeras digitais de vídeo, contando com os recursos da web para imediata publicação ou envio de material.

Anthony Seeger nota que "arquivos audiovisuais e coleções audiovisuais mantidas em instituições de natureza diversa apresentam problemas muito específicos quanto à preservação e ao acesso. A maioria dos arquivos de papel inclui, hoje, coleções cada vez maiores de áudio e de vídeo". ${ }^{23}$ Essas coleções, por sua vez, devem ceder às demandas da digitalização.

Quando Walter Benjamin escrevia sobre a era da reprodutibilidade técnica da obra de arte, no início da década de $1930^{24}$, provavelmente não alcançava a dimensão de um impensável futuro marcado pela tecnologia, que hoje se caracteriza pela era digital e pelo universo virtual. A quantidade incalculável de imagens virtuais que atravessam nosso cotidiano parece tornar esse material vulnerável e fugaz, suscetível a desaparecer ao toque de uma tecla de computador ou a não mais alcançar qualquer materialidade. Seria este o futuro dos acervos acadêmicos confiados aos repositórios virtuais?

Refletir sobre questões como esta também é parte do trabalho dos historiadores e historiadoras, envolvidos inelutavelmente com os dilemas e problemas da tecnologia, como veremos a seguir.

\section{DESAFIOS}

Os desafios do nosso tempo e do nosso ofício passam obrigatoriamente pelo manejo e domínio da tecnologia informática, presente em todos os meios por onde transita a prática de pesquisa histórica e a historiografia. Como lidar com isso na constituição e na divulgação de um acervo acadêmico de pesquisa é tema de um debate no qual buscamos nos inserir.

\section{ACERVOS FÍSICOS, DIGITAIS E VIRTUAIS - PERMANÊNCIA OU FUGACIDADE DOS DOCUMENTOS?}

Há alguns anos, Bacellar argumentava a respeito dos recursos digitais:

Após a proliferação da informática, arautos da modernidade vendiam a ideia de que as novas máquinas pensantes iriam dar fim à produção de papéis, principalmente quando do advento da internet e das redes de computadores. A documentação se tornaria virtual, sem suporte em papel. Hoje a realidade é bastante distinta dessas previsões profundamente otimistas. ${ }^{25}$ 
Bacellar observa ainda que a maioria dos arquivos públicos pouco disponibiliza de informação via web, o que gera a necessidade do deslocamento físico até os arquivos. ${ }^{26}$ Adriana Hollós oferece uma contrapartida ao constatar que, a partir dos anos 2000, cresceu aceleradamente o volume de documentos gerados em meio digital. Isso traz novas perspectivas para a atividade de preservação documental e mudança de paradigmas nas formas de atuação. ${ }^{27}$

Longe de pensar que os computadores substituiriam totalmente os acervos compostos por papéis e outros materiais, insistimos também numa visão otimista ao considerarmos os caminhos aos quais a digitalização pode levar. É certo que uma 'nuvem' virtual jamais vai sofrer com incêndios ou enchentes, seus back-ups alojados em equipamentos físicos talvez sim. As 'panes' de sistemas são passíveis de acontecer, mas os recursos que hoje oferecem cópias de segurança (back-ups) virtuais da documentação podem dar origem a uma preservação de documentos bastante segura. Ainda assim, não podemos afirmar que a internet será a forma mais interessante de se lidar com a documentação. ${ }^{28}$

A desconfiança dos sistemas de informática ainda mantém certa tradição. Para Adriana Hollós, é um desafio preservar as estruturas dos arquivos em termos de conteúdo e ambiência tecnológica. "No mundo atual, a maior parte da informação produzida está sendo gerada nos computadores, em diferentes formatos, como texto, banco de dados, áudio, filme e imagem. Esses documentos, nascidos digitais, constituem-se um desafio de preservação ainda maior". ${ }^{29}$ A transitoriedade das novas tecnologias, que rapidamente tornam-se obsoletas, está no foco de sua preocupação. "Tal ambiente tecnológico, onde os documentos fazem moradia, é constantemente alterado e substituído por força de um mercado que continua lançando novas gerações de equipamentos e softwares que, ao final, podem se tornar incompatíveis com os que the antecederam" $" 30$ - pondera Hollós.

Sobre essa questão, Seeger considera que a "mudança de formatos de vídeo exige que os arquivos disponham de uma grande quantidade e variedade de aparelhos de reprodução." O autor também percebe uma falta de preocupação das empresas com relação à durabilidade dos programas visando a preservação de documentos. ${ }^{31}$

A problematização da conformação de acervos digitais torna-se pertinente ao atentar não só para as maneiras dessa constituição, mas também para sua necessidade de preservação e proteção. Gabriel Bevilacqua argumenta sobre a integração definitiva das ferramentas informáticas na administração dos arquivos, exigindo um trabalho conjunto com os profissionais de tecnologia da informação (TI). Para Bevilacqua, "a nova perspectiva da preservação de arquivos eletrônicos, pautada em sua imensa fragilidade de permanência, aproxima brutalmente o momento de preocupação com sua conservação ao do seu nascimento ou produção." Essas características tornam urgentes os cuidados de guarda e preservação. ${ }^{32}$ 
Segundo Seeger, diferentemente das gravações comerciais, que geram várias cópias, guardadas em diferentes instituições, a maioria das gravações documentais é registrada em exemplar único, mantido em apenas uma instituição. Quando o material já não pode ser reproduzido, os sons se perdem para sempre. "A fragilidade disso a que chamo 'registros de campo' (gravações únicas, realizadas durante uma pesquisa) independe do formato em que os sons tiverem sido originalmente gravados e da mídia em que se encontrem presentemente preservados." Os aparelhos de áudio antigos sofrem uma rápida degradação; muitos dos mais novos se mantêm confiáveis apenas durante alguns anos. Para Seeger, "os hoje populares suportes digitais estão entre os menos estáveis, e a instabilidade tem aumentado conforme se desenvolvem novos formatos para o consumidor". ${ }^{33}$

$\mathrm{Na}$ era digital/virtual, a maior preocupação dos historiadores continua sendo com suas fontes. Para o uruguaio Juan Andrés Bresciano,

\begin{abstract}
No processo de geração de conhecimento científico sobre o passado, a existência e disponibilidade de fontes resulta um dos fatores determinantes. Entendidas como todos aqueles objetos materiais, instrumentos ou ferramentas, símbolos ou discursos, através dos quais se pode "inferir algo sobre uma determinada situação social no tempo", as fontes estabelecem os limites do possível para os alcances de uma investigação histórica qualquer. Sua conservação muitas vezes contingente e desigual, sua variedade casual e frequentemente desequilibrada, sua escassez ou sua abundância sempre relativas, estabelecem, em algumas ocasiões, obstáculos ao conhecimento, nem sempre fácil de se superar. Por este motivo, a preservação e sistematização de fontes constitui uma das preocupações técnicometodológicas mais urgentes das Ciências Históricas. ${ }^{34}$
\end{abstract}

Os acervos digitais e virtuais, ao contrário de representarem uma ameaça para as fontes de pesquisa histórica, apresentam-se como uma opção em benefício da preservação de tais documentos - esta, uma obsessão para os profissionais do campo da História. A organização e a digitalização dos documentos acontecem como trabalho intermediário entre o material físico e seu suporte virtual. $\mathrm{O}$ que se faz necessário é um trabalho de organização e atualização permanente, no sentido de estar em dia com as tecnologias que surgem o tempo todo. Esta prática requer a disponibilidade de profissionais ou bolsistas dos núcleos de pesquisa.

Peter Burke nos chama a atenção para esse aspecto, ao considerar a impossibilidade de se estudar o passado sem uma assistência de toda uma cadeia de intermediários, "incluindo não apenas os primeiros historiadores, mas também os arquivistas que organizaram os documentos, os escribas que 
os escreveram e as testemunhas cujas palavras foram registradas". ${ }^{35}$ Está traçada uma aproximação entre história e arquivística ${ }^{36}$, que certamente não foi 'inventada' nos dias atuais, mas que se insere no cotidiano dos núcleos de pesquisa. Podemos dizer que uma rede de atividades está na base da constituição desses acervos. Dela fazem parte entrevistados, historiadores, arquivistas, bolsistas - sujeitos situados historicamente e que ligam, por meio de suas atividades específicas, todas as partes do processo. Por isso são considerados essenciais dentro da proposta deste artigo.

Para Bresciano, a informatização tornou-se decisiva em vários âmbitos, principalmente na classificação e organização dos fundos de documentação, e sua posterior disponibilização para consulta à distância. ${ }^{37}$ "Sem dúvida, a automatização contribui para que o serviço melhore qualitativamente em sua qualidade e que se amplie o número de consultantes atendidos e de consultas realizadas, sem que seja afetada a documentação"38, de acordo com o autor.

Disponibilizar a documentação acumulada e os resultados da pesquisa para consulta pública significa de certo modo atingir um objetivo quando há o compromisso de se produzir conhecimento visando sua democratização e o alcance de um público maior, para além dos limites da academia. Esta é a real possibilidade aberta a partir da apropriação dos recursos informáticos pelos núcleos acadêmicos que reúnem acervos.

A ideia aqui apresentada agrega elementos transdisciplinares quando busca apoio no campo da arquivologia, tateando caminhos entre autores que já colocaram em questão a conformação de arquivos destinados à pesquisa. ${ }^{39}$ José Maria Jardim, por exemplo, trabalha sobre "a invenção da memória nos arquivos públicos" ${ }^{\prime 40}$ e sua dimensão política.

Tratou-se de observar como a noção/conceito de memória tende a ser teoricamente referida, quando do processo de avaliação e seleção de documentos arquivísticos, como um dos pilares da arquivologia contemporânea. A este processo e seus determinantes teóricos encontra-se vinculada, por princípio, a constituição dos acervos permanentes/históricos dos arquivos públicos. Estes escolhem, mediante tais diretrizes, documentos considerados socialmente relevantes a ponto de se justificar a sua preservação permanente. ${ }^{41}$

Notamos em suas palavras a centralidade da memória vinculada à constituição de acervos permanentes, além da hierarquização dos documentos como "socialmente relevantes". Talvez a classificação de documentos trace uma distinção entre os campos da história e da arquivologia, mas nos interessa essa compreensão de como a constituição de acervos aparece permeada pelas práticas arquivística e historiográfica.

Nos anos 1980, Jacques Le Goff ${ }^{42}$ já atentava para a centralidade da memória, provocando reflexões a respeito do tempo e do espaço, do suporte e 
do sentido, da memória individual ou coletiva, do acaso ou da intencionalidade. Paralelamente, a constituição de bibliotecas e arquivos passava a fornecer material para a história. Desde Le Goff, outras questões foram sendo colocadas ${ }^{43}$, inserindo esta matéria-prima volátil no campo de atuação dos historiadores.

Pierre Nora também ajuda a pensar sobre a memória que se constitui em memória arquivística, resultando em um "estoque material daquilo que nos é impossível lembrar" ${ }^{44}$ Para José Maria Jardim, a noção de "arquivo permanente" expressa um tipo de memória materializada. "Como tal, esta memória confunde-se com o próprio arquivo a ser preservado. $\mathrm{O}$ arquivo permanente tende a ser definido na literatura da área como 'os conjuntos de documentos de valor histórico, probatório e informativo que devem ser definitivamente preservados". ${ }^{45}$

Seeger complementaria: "Dado que arquivos buscam aprimorar o acesso a suas coleções, é muito importante pensar para além das questões técnicas relativas a formatos de digitalização de informação e a catalogação.” Os acervos de pesquisa também têm de resolver incontornáveis questões de direitos de propriedade intelectual e dos novos tipos de relacionamento com as pessoas cujas performances estão neles registradas. Apenas lidando, a um só tempo, com acesso, direitos e preservação, é que começarão a instrumentalizar esses corpos documentais de modo que possam servir, no presente e no futuro, às expectativas e às vidas das pessoas. ${ }^{46}$

Entendemos que os desafios mencionados por Seeger perpassam a constituição de acervos acadêmicos dentro de laboratórios de estudo e pesquisa. Estes acervos certamente representam interesses específicos de cada grupo, porém, como conjunto, podem oferecer à comunidade um material de pesquisa que instigue e possibilite o acesso simplificado, despertando o interesse por aquilo que é produzido no âmbito acadêmico, abrindo assim um veio para o retorno à sociedade do que é constituído a partir de sua própria experiência.

Para Bevilacqua, além da função de vincular de forma contínua ações, trajetórias e processos de uma instituição, "os arquivos também possibilitam, através de suas qualidades informativas e representativas únicas, o importante diálogo com a comunidade aonde se insere a organização". ${ }^{47}$

Dentro da comunidade acadêmica, a troca de experiências entre laboratórios, envolvendo seus estudantes e professores, pode auxiliar no domínio de técnicas e práticas que facilitem o trabalho, promovendo a organização e posterior divulgação dos resultados das pesquisas. Pensar a universidade hoje é pensar em termos de integração e apoio mútuo, e quem sabe vislumbrar práticas de ensino intermediadas também por acervos acadêmicos. 


\section{ACERVOS, PESQUISA E ESCRITA DA HISTÓRIA}

Chegamos então, e para finalizar, às relações entre prática historiográfica e acervos de pesquisa, onde é buscado material de apoio para se levar adiante uma investigação. O "ofício do historiador" (lembrando Bloch) desloca-se de um escritório, do trabalho solitário e individual, que ainda é realizado, mas que vai se juntar a outros trabalhos de uma mesma esfera de interesses. Professores e estudantes depositam em seus laboratórios ou núcleos o material colhido ou registrado por cada pesquisa. ${ }^{48}$ Os acervos assim constituídos apresentam, em nossos dias, características e conteúdos que são ao mesmo tempo físicos, digitais e virtuais.

Muitas vezes são as bolsas de produtividade e seus projetos que proporcionam ou incentivam a constituição de acervos, que são retroalimentados por viagens, livros e equipamentos adquiridos, que acabam desembocando em produção acadêmica. As metas, por vezes questionáveis, ${ }^{49}$ para se manter um nível elevado de produção, fazem abastecer revistas científicas com a produção contínua de conhecimento. É justo que a qualidade dessa produção seja observada e avaliada.

A produção e o acúmulo de fontes como acervos acadêmicos de pesquisa trazem implicitamente um compromisso, que é o retorno da produção científica resultante às comunidades envolvidas, cujas histórias encontramse em parte sob a tutela desses núcleos universitários. Ao concederem uma entrevista, podemos considerar que as pessoas têm no horizonte sua divulgação, portanto, o reconhecimento da relevância daquilo que têm a dizer. A prática historiográfica se depara também com uma questão ética, que na maioria das vezes não é mostrada de forma explícita: a devolução do material produzido aos grupos ou indivíduos que possibilitaram forjar documentos para a pesquisa e produção historiográfica.

Entendemos, como Anthony Seeger, que entre os potenciais usuários de arquivos, os mais importantes haveriam de ser as comunidades que têm parte de seus registros guardada nos acervos..$^{50} \mathrm{E}$ não falamos aqui apenas em entrevistas, mas também em material iconográfico e outros tipos de documentos.

Visando uma integração e a consulta mais rápida e eficiente aos acervos de pesquisa localizados em âmbito universitário, seria possível pensarmos em termos de uma rede de arquivos acadêmicos digitalizados, agregando núcleos de pesquisa em torno de questões técnicas, como procedimentos de armazenamento e publicação dos dados componentes desses acervos em um repositório virtual.

Essas reflexões juntam-se a outras e ficam como uma proposta a ser aprofundada por profissionais e estudantes interessados em integração, trocas e na democratização do conhecimento produzido na academia, e que estejam dispostos a romper com as barreiras impostas por linhas de pesquisas adotadas 
por núcleos que acabam trabalhando apenas no entorno de interesses próprios, fechando-se sobre suas produções. A possibilidade de uma apropriação mais ampla dos acervos, uma relação mais estreita entre os núcleos, as universidades e a comunidade está no horizonte das discussões propostas neste artigo, como meta privilegiada da produção e divulgação de conhecimento científico no campo da pesquisa histórica.

\section{NOTAS}

${ }^{1}$ HEYNEMANN, Cláudia B. A história e os arquivos: anotações à margem do documento. Ponto de Acesso, Salvador, v.3, n.1, p. 66, abr. 2009.

2 POMIAN, K. apud HEYNEMANN. Ibidem, p. 70.

3 Ibidem.

${ }^{4}$ BACELLAR, Carlos. Uso e mau uso dos arquivos. In: PINSKY, Carla Bassanezi (Org.). Fontes históricas. 2 ed. São Paulo: Contexto, 2010. p. 50.

5 Ibidem, p. 69.

${ }^{6}$ De acordo com Le Goff, somos nós, historiadores, que erigimos nossos próprios monumentos, de acordo com um interesse particular. LE GOFF, Jacques. Documento/Monumento. In: . Memória e História. São Paulo: Ed. Unicamp, 1992. p. 525-541.

${ }^{7}$ FOUCAULT, Michel. Vigiar e Punir: Nascimento da Prisão. 25 ed. Petrópolis: Vozes, 1997.

${ }^{8}$ FOUCAULT, Michel. A ordem do discurso. São Paulo: Edições Loyola, 2003.

9 SEEGER, Anthony. Uma história de dois arquivos: aquisição, preservação, digitalização e divulgação de acervos audiovisuais. Revista IEB, n. 48, p. 36, mar. de 2009.

${ }^{10}$ Ibidem.

${ }^{11}$ FARGE, Arlette. O sabor do arquivo. São Paulo: Edusp, 2009. p. 21-22.

${ }^{12}$ SEEGER, op. cit., p. 39.

${ }^{13}$ Seeger refere-se ao trabalho com arquivos sonoros, cuja tecnologia mais remota nas gravações era o cilindro de cera, sendo seguido pelo disco de vinil e este pela fita de rolo e fitas cassete. Ibidem, p. 39. Só mais tarde entram nos estúdios de reprodução os CDs e os DVDs, e, mais recentemente alguns tipos de tecnologia digital, como os formatos MP3, wave, etc.

${ }^{14}$ POLLAK, Michel. Memória, Esquecimento, Silêncio. Estudos Históricos, Rio de Janeiro, v. 2, n. 3, p. 3-15, 1989.

${ }^{15}$ PORTELLI, Alessandro. A filosofia e os fatos: narração, interpretação e significado nas memórias e nas fontes orais. Tempo, Rio de Janeiro, v. 1, n. 2, p. 72, 1996.

${ }^{16}$ RAGO, Margareth. A aventura de contar-se: feminismos, escrita de si e invenções da subjetividade. Campinas, SP: Ed. Unicamp, 2013. p. 30.

${ }^{17}$ LEJEUNE, Philippe. O pacto autobiográfico: de Rousseau à internet. Belo Horizonte: Ed. UFMG, 2008.

${ }^{18}$ BOURDIEU, Pierre. A ilusão biográfica. In: FERREIRA, Marieta de Moraes; AMADO, Janaína. Usos \& Abusos da História Oral. 2 ed. Rio de Janeiro: Fundação Getúlio Vargas, 
1998. p. 184-185.

${ }^{19}$ Diversos artigos sobre história oral encontram-se em um livro que virou referência para o campo no Brasil. Trata-se de AMADO, Janaína; FERREIRA, Marieta de Morais. Usos \& abusos da História Oral. Rio de Janeiro: FGV, 1998.

${ }^{20}$ Sobre cultura visual, cf. MENESES, Ulpiano B. Fontes visuais, cultura visual, história visual. Balanço provisório, propostas cautelares. Revista Brasileira de História, São Paulo, v. 23, n. 45, 2003. Disponível em: <http://www.scielo.br/pdf/rbh/v23n45/16519.pdf>.

${ }^{21}$ SEEGER, op. cit., p. 40.

${ }^{22}$ BURKE, Peter. Testemunha ocular: história e imagem. Bauru: EDUSC, 2004. p. 20.

${ }^{23}$ SEEGER, op. cit., p. 31.

${ }^{24}$ BENJAMIN, Walter. A obra de arte na era de sua reprodutibilidade técnica. In.

Magia e técnica, arte e politica - obras escolhidas. São Paulo: Brasiliense, 2008. $\overline{\text { p. 165-196. }}$

${ }^{25}$ BACELLAR, op. cit., p. 47.

${ }^{26}$ Ibidem, p. 51.

${ }^{27}$ HOLLÓS, Adriana Cox. Fundamentos da Preservação Documental no Brasil. Acervo, Rio de Janeiro, v. 23, n. 2, p. 23, jul./dez. 2010.

${ }^{28}$ Cf. HAAG, Carlos. Uma incômoda pitada de magia. Revista Pesquisa FAPESP, ed. 199, set. 2012. Disponível em: $<$ http://revistapesquisa.fapesp.br/2012/09/14/uma-incomoda-pitadade-magia>.

${ }^{29}$ Ibidem, p. 28.

${ }^{30}$ Ibidem, p. 29.

${ }^{31}$ SEEGER, op. cit., p. 35.

${ }^{32}$ BEVILACQUA, Gabriel M. F. Bancos de dados e informatização de arquivos: pressupostos teóricos e aplicações técnicas. 2010. Dissertação (Mestrado em História Social) - Faculdade de Filosofia, Letras e Ciências Humanas, Universidade de São Paulo, São Paulo, 2010, p. 3.

${ }^{33}$ SEEGER, op. cit., p. 34.

${ }^{34}$ BRESCIANO, Juan Andrés. El historiador, los archivos y los medios informáticos. p. 157. "En el proceso de generación de conocimiento científico sobre el pasado, la existencia y disponibilidad de fuentes resulta uno de los factores determinantes. Entendidas como todos aquellos objetos materiales, instrumentos o herramientas, símbolos o discursos, a cuyo través puede "inferirse algo acerca de una determinada situación social en el tiempo", las fuentes establecen los límites de lo posible para los alcances de una investigación histórica cualquiera. Su conservación mucha veces contingente y desigual, su variedad azarosa y frecuentemente desequilibrada, su escasez o su abundancia siempre relativas, establecen, en algunas ocasiones, obstáculos al conocimiento no siempre fáciles de superar. Por este motivo, la preservación y sistematización de fuentes constituye una de las preocupaciones técnico-metodológicas más acuciantes de las Ciencias Históricas.” Tradução livre.

${ }^{35}$ BURKE, op. cit., p. 16.

${ }^{36}$ Sobre a relação entre arquivística e história, cf. tb., neste dossiê, VIANA JÚNIOR, Mário M.; NOGUEIRA, Antonio G. R. Acervos de pesquisa: espaços de geração de sentido histórico.

${ }^{37}$ BRESCIANO, op. cit., p. 161. 
${ }^{38}$ Ibidem, p. 167. "Indudablemente, la automatización contribuye a que la puesta en servicio mejore cualitativamente en su calidad, y que se amplíe el número de consultantes atendidos y de consultas realizadas, sin que por ello resulte afectada la documentación." Tradução livre.

${ }^{39}$ Entre eles, cf. MAKHLOUF, Basma; CAVALCANTE, Lídia Eugenia. Avaliação arquivística: bases teóricas, estratégias de aplicação e instrumentação. Encontros Bibli, v. 13, n. 26, 2008. Disponível em: <http://journal.ufsc.br/index.php/eb/article/download/15182924.2008v13n26p201/6646>. LACERDA, Aline Lopes de. A fotografia nos arquivos: a produção de documentos fotográficos da Fundação Rockefeller durante o combate à febre amarela no Brasil. 2008. Tese (Doutorado em História Social) - Faculdade de Filosofia, Letras e Ciências Humanas, Universidade de São Paulo, São Paulo, 2008.

${ }^{40}$ JARDIM, José M. A invenção da memória nos arquivos públicos. Ciência da Informação, v. 25 , n. 2, 1995.

${ }^{41}$ Ibidem.

${ }^{42}$ LE GOFF, Jacques. História e memória. Trad. Bernardo Leitão. 5 ed. Campinas: Ed. UNICAMP, 2003.

${ }^{43}$ Cf. RICOEUR, Paul. A memória, a história, o esquecimento. Campinas, SP: Ed. UNICAMP, 2000.

${ }^{44}$ NORA, Pierre. Entre Memória e História: a problemática dos lugares. Projeto História, São Paulo, n. 10, p. 15, dez. 1993.

${ }^{45}$ JARDIM, op. cit.

${ }^{46}$ SEEGER, op. cit., p. 52.

${ }^{47}$ Ibidem.

${ }^{48}$ Mesmo que essa etapa aconteça no momento posterior à publicação de resultados, em forma de artigo, tese ou livro.

${ }^{49}$ Questionáveis, a partir do momento que é possível se encontrar artigos com diferentes títulos, de um mesmo autor e publicados em revistas variadas, que tratam de questões muitas vezes similares.

${ }^{50}$ SEEGER, op. cit., p. 38.

Artigo recebido em junho de 2014. Aceito em agosto de 2014. 